BMJ Open

Diabetes

Research

\& Care

\section{Inner ear is a target for insulin signaling and insulin resistance: evidence from mice and auditory HEI-OC1 cells}

To cite: Pålbrink A-K, Kopietz F, Morén $\mathrm{B}$, et al. Inner ear is a target for insulin signaling and insulin resistance: evidence from mice and auditory HEI-OC1 cells. BMJ Open Diab Res Care 2020;8:e000820. doi:10.1136/ bmjdrc-2019-000820

- Additional material is published online only. To view, please visit the journal online (http://dx.doi.org/10.1136/ bmjdrc-2019-000820).

Received 13 August 2019 Revised 14 February 2020 Accepted 3 March 2020
Check for updates

(c) Author(s) (or their employer(s)) 2020. Re-use permitted under CC BY-NC. No commercial re-use. See rights and permissions. Published by BMJ.

For numbered affiliations see end of article.

Correspondence to Dr Eva Degerman; eva.degerman@med.lu.se

\section{ABSTRACT}

Objective The mechanisms underlying the association between diabetes and inner ear dysfunction are not known yet. The aim of the present study is to evaluate the impact of obesity/insulin resistance on inner ear fluid homeostasis in vivo, and to investigate whether the organ of Corti could be a target tissue for insulin signaling using auditory House Ear Institute-Organ of Corti 1 (HEl-OC1) cells as an in vitro model.

Methods High fat diet (HFD) fed C57BL/6J mice were used as a model to study the impact of insulin resistance on the inner ear. In one study, 12 C57BL/6J mice were fed either control diet or HFD and the size of the inner ear endolymphatic fluid compartment (EFC) was measured after 30 days using MRI and gadolinium contrast as a read-out. In another study, the size of the inner ear EFC was evaluated in eight C57BL/6J mice both before and after HFD feeding, with the same techniques. HEI-OC1 auditory cells were used as a model to investigate insulin signaling in organ of Corti cells.

Results HFD feeding induced an expansion of the EFC in C57BL/6J mice, a hallmark of inner ear dysfunction. Insulin also induced phosphorylation of protein kinase $B$ (PKB/Akt) at Ser473, in a PI3-kinase-dependent manner. The phosphorylation of PKB was inhibited by isoproterenol and IBMX, a general phosphodiesterase (PDE) inhibitor. PDE1B, PDE4D and the insulin-sensitive PDE3B were found expressed and catalytically active in HEI-OC1 cells. Insulin decreased and AICAR, an activator of AMPactivated protein kinase, increased the phosphorylation at the inhibitory Ser79 of acetyl-CoA carboxylase, the rate-limiting enzyme in de novo lipogenesis. Furthermore, the activity of hormone-sensitive lipase, the rate-limiting enzyme in lipolysis, was detected in HEI-OC1 cells.

Conclusions The organ of Corti could be a target tissue for insulin action, and inner ear insulin resistance might contribute to the association between diabetes and inner ear dysfunction.

\section{INTRODUCTION}

Ample evidence shows that type 1 and type 2 diabetes negatively impact on the function of the vestibular and auditory systems both in humans and in animal models. ${ }^{1-5}$ Although several theories have been proposed (eg, microangiopathy, advanced glycation end

\section{Significance of this study}

What is already known about this subject?

- As has been summarised in reviews and metaanalysis studies, there is an association between diabetes and inner ear dysfunction; the mechanisms lying beneath this association, however, are not known

- We have previously shown that cells from the human inner ear sensory epithelium express the insulin receptor as well as insulin signaling components.

- Now we wonder: Does insulin direct action, or defects in insulin-triggered signaling, contribute to hearing dysfunction in diabetes?

What are the new findings?

- Insulin impacts on inner ear functions by mechanisms classically associated with insulin signaling in target cells.

- Inner ear insulin resistance might contribute to diabetes-associated inner ear dysfunction.

How might these results change the focus of research or clinical practice?

- Pure tone audiometry, auditory brain stem response and distortion products otoacustic emissions, conventional testing methods for early diagnosis of hearing loss, could be used in the following up of patients with diabetes to prevent further disease progression of inner ear functions.

products, reactive oxidative stress and mitochondrial dysfunction, demyelination of the auditory nerve, spiral ganglion loss and atrophic changes of organ of Corti cells ${ }^{5-9}$ ), the exact underlying mechanisms responsible for diabetes-induced damage to the auditory system remain uncertain.

The progression of hearing loss in mice with type 1 diabetes induced with streptozotocin or type 2 diabetes induced with high fat die (HFD), respectively, has been reported to have different characteristics as measured by auditory brain stem response and distortion products otoacustic emissions (DPOAE).$^{10}$ 
Furthermore, hyperinsulinemia, a marker for insulin resistance and type 2 diabetes, has been suggested to explain differences in dysfunction of specific auditory pathways in the two types of diabetes in a comprehensive neuro-electrophysiological study in mice. ${ }^{11}$ In humans, insulin resistance, impaired fasting glucose and betacell dysfunction have been reported as independent risk factors for hearing impairment even before the onset of type 2 diabetes. ${ }^{12}$ Thus, a number of studies are in agreement with reports showing harmful effects of induced hyperinsulinemia on inner ear metabolic and ion homeostasis. ${ }^{13-16}$

The role of the cochlea as a direct target organ for insulin action has not been well characterized. Recently, it was reported that the insulin receptor is expressed specifically in supporting cells of the organ of Corti ${ }^{17}$ in agreement with early studies showing high affinity binding sites for insulin in the cochlea. ${ }^{18}$ Also, previous results from our laboratory demonstrated the expression of the insulin receptor, insulin receptor substrate 1 , protein kinase $\mathrm{B}(\mathrm{PKB} / \mathrm{Akt})$, the insulin-sensitive phosphodiesterase (PDE) 3B as well as targets such as the insulin-regulated glucose transporter 4 , in the sensory epithelium of the human saccule. ${ }^{1920}$

The C57BL/6 mouse strain fed HFD is a commonly used animal model for studies of the pathophysiology of insulin resistance, impaired glucose homeostasis and early type 2 diabetes. ${ }^{21}$ In the present study, we investigated the impact of insulin resistance on the size of the cochlear endolymphatic fluid compartment (EFC) in vivo in HFD-fed C57BL/6J mice using MRI with contrast. Endolymphatic hydrops (EH), an expansion of the EFC, was looked on as a marker for risk to develop cochlear dysfunction. We have previously used MRI and gadolinium contrast to demonstrate that $\mathrm{EH}$ develops in response to treatment with vasopressin and family selective PDE inhibitors, cilostamide, rolipram and sildenafil, respectively ${ }^{202}$ and furthermore shown that hydrops can be prevented by spironolactone administration under specific conditions. ${ }^{23}$

To study insulin signaling in vitro, House Ear InstituteOrgan of Corti 1 (HEI-OC1) auditory cells, one of the few auditory cell lines available for research purposes, were used. ${ }^{24}$ HEI-OC1 cells are considered a model for organ of Corti cells since they express markers for both hair cells and supporting cells.

\section{METHODS}

\section{Animals and high fat diet interventions}

A total of 20 female, 8 weeks of age, C57BL/6J mice (Taconic, Denmark) were on a 12 hours light cycle with non-restricted food and water intake.

Study 1: six C57BL/6J mice were fed HFD (D12492, 60 E\% fat content; Research Diets, New Brunswick, New Jersey, USA) and six mice were fed control diet (CD) for 30 days. Thereafter, the areas of the EFCs were evaluated using MRI with gadolinium contrast as described in Magnetic resonance imaging.

Study 2: eight C57BL/6J mice were fed HFD for 30 days. The areas of the EFC were evaluated twice for each mouse, both before and after 30 days of HFD, using MRI with gadolinium contrast.

\section{Magnetic resonance imaging}

Animals were anesthetized with $3.5 \%$ isoflurane in a mixture with $200 \mathrm{~mL} / \mathrm{min}$ oxygen and $200 \mathrm{~mL} / \mathrm{min}$ nitrous oxide and maintained at 1.5\%-2\% isoflurane inside the magnet. Gadolinium contrast agent (Dotarem, Guerbet, Villepinte, France) (gadoteric acid, $279.3 \mathrm{mg}$ / $\mathrm{mL}, 0.5 \mathrm{mmol} / \mathrm{mL}$ ) was administered intraperitoneally $(100 \mu \mathrm{g} / 20 \mathrm{~g})$ in the left abdominal quadrant $55-65 \mathrm{~min}$ before MRI. The induction chamber was kept warm at $37^{\circ} \mathrm{C}$. Inside the magnet, the respiratory rate of the animal was monitored (SA Instruments, New York, USA) and the body temperature was maintained using a Lauda Rc6 CS recirculating water bath (Köningshofen, Germany).

MRI was performed as previously described ${ }^{20} 2223$ with a 9.4 T magnet (Agilent, Palo Alto, USA) using Avance III electronics (Bruker, Ettlingen, Germany). The system is equipped with a $12 \mathrm{~cm}$ inner diameter gradient system having a maximum gradient strength of $670 \mathrm{mT} / \mathrm{m}$. The animals were imaged using a quadrature transmit/receive cryoprobe (Bruker). T1-weighted three-dimensional (3D) images were acquired with a gradient echo 3D sequence; repetition time TR: $11 \mathrm{~ms}$, echo time TE: 3.695 ms, number of averages: 2 , data matrix size $220 \times 220 \times 147$ pixels, field of view $15 \times 15 \times 10 \mathrm{~mm}^{3}$. Images were reconstructed by zero filling to increase the apparent resolution of the image to a matrix size of $440 \times 440 \times 294$ pixels and an apparent pixel resolution of $0.034 \mathrm{~mm}$.

\section{Quantitative assessment of gadolinium in the endolymphatic} relative to the perilymphatic space

Synedra view personal 16 (Synedra, Innsbruck, Austria), as well as Adobe Photoshop CS5 (Adobe, San Jose, USA), were used for postproduction processing of images, for the quantification of signal intensity in regions of interest and for labeling and demonstration of perilymph in the scala tympani (ST) and scala vestibule (SV) and endolymph in the scala media (SM). Images parallel to the modiolus of mouse cochleae were used for measurements. ${ }^{20223}$ To evaluate the effect of various treatments on the size of the EFC, the relative area of SM in the basal turn of the cochlea was estimated by calculating the ratio between SM (endolymph, non-contrast enhanced) and SM plus SV (perilymph, contrast enhanced). The ratio of areas was subsequently converted to percentage as shown in figures 1 and 2. The observer assessing and outlining the perilymphatic and endolymphatic sizes, was blinded to the treatments given.

\section{HEI-0C1 auditory cells and cullture}

HEI-OC1 cells were cultured in 6-well plates (6-well TC (tissue culture) plate standard, Sarstedt, Numbrecht, 

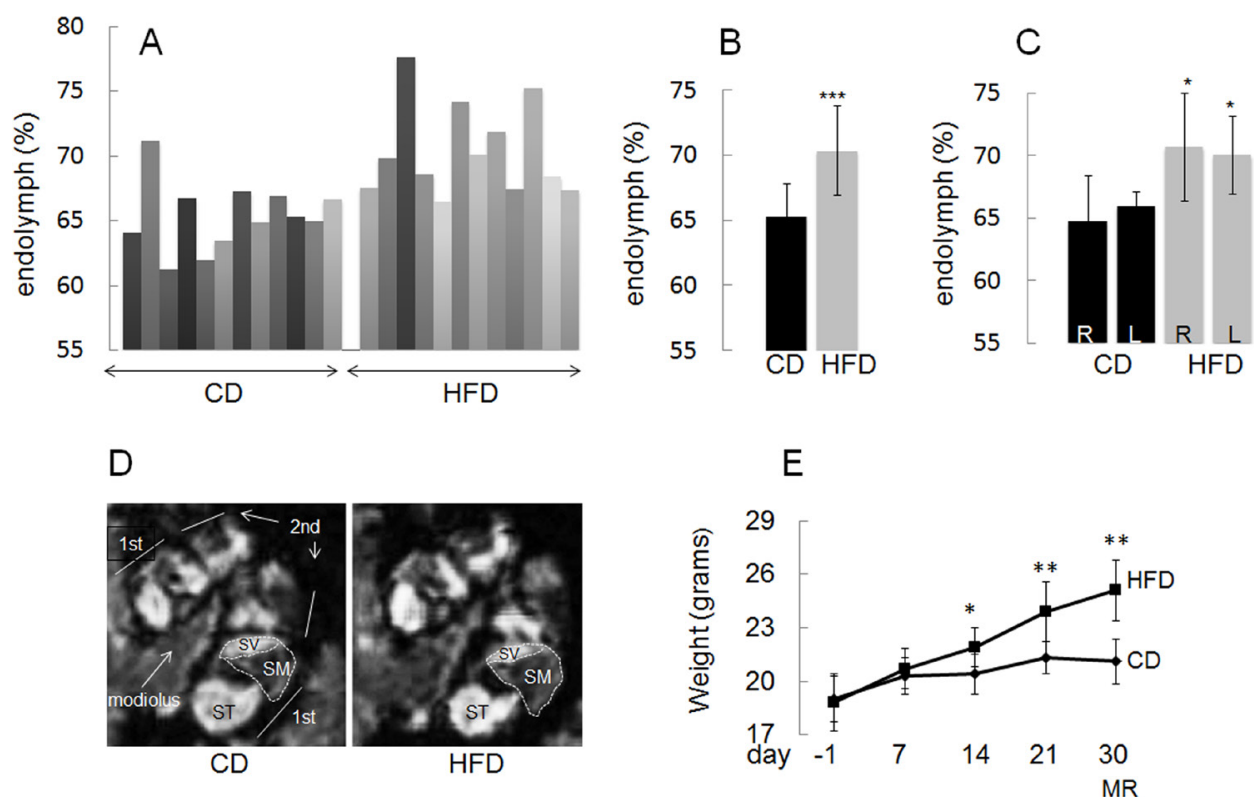

Figure 1 High fat diet (HFD) feeding induces expansion of the endolymphatic fluid compartment in C57BL/6J mice as compared with mice fed control diet (CD). (A) Relative areas of endolymphatic compartments in individual ears. (B) Ears in the CD and HFD groups (mean \pm SEM: $65.3 \pm 2.5$ and $70.4 \pm 3.4$, respectively; $p=0.00088$ ). (C) Right and left ears in CD and HFD groups (mean \pm SEM: $64.7 \pm 3.7$ and $70.7 \pm 4.3 ; p=0.028$ for right ears and $66.0 \pm 1.1$ and $70.0 \pm 3.1 ; p=0.011$ for left ears). $R$, right; L, left. (D) Example of images parallel to the modiolus of cochlea of mice fed HFD or CD analyzed by MRI is shown. The gadolinium contrast moves into the perilymph (SV and ST), but not into the endolymph (SM), therefore the perilymph looks white and the endolymph looks black. Note the significant decrease in SV relative area after HFD feeding. The relative area of SM in the basal turn of the cochlea was estimated as described in 'Methods' section. The ratio of areas was subsequently converted to percentage as shown in A-C. SV, scala vestibule; ST, scala tympani; SM, scala media; 1st, first turn; 2nd, second turn. (E) Time course in changes in body weight from baseline at 8 weeks of age and during 30 days on CD (six mice) and HFD (six mice). MRI was performed at day indicated. Data are presented as means $\pm S D .{ }^{*} P<0.05,{ }^{* *} p<0.01,{ }^{* \star *} p<0.001, H F D$ vs $C D$.

Germany) under permissive conditions $\left(33^{\circ} \mathrm{C}, 10 \% \mathrm{CO}_{2}\right)$ in high-glucose Dulbecco's Modified Eagle Medium (Sigma) containing $10 \%$ fetal bovine serum (Sigma) without antibiotics. ${ }^{24}$ After reaching $70 \%-80 \%$ confluence cells were washed twice with phosphate-buffered saline and preincubated for 2 hours in Krebs-Ringer bicarbonate buffer containing $2 \mathrm{mM}$ glucose, $10 \mathrm{mM}$ HEPES, $\mathrm{pH} 7.4,120 \mathrm{mM} \mathrm{NaCl}, 5 \mathrm{mM} \mathrm{NaHCO}, 5 \mathrm{mM} \mathrm{KCl}, 1.2 \mathrm{mM}$ $\mathrm{KH}_{2} \mathrm{PO}_{4}, 2.5 \mathrm{mM} \mathrm{CaCl}_{2}, 1.2 \mathrm{mM} \mathrm{MgSO}$ and $0.2 \%$ bovine serum albumin (BSA). Thereafter, fresh buffer was added and cells were treated as indicated in the 'Results' section. After treatments, the cells were harvested in a buffer containing $50 \mathrm{mM}$ TES (N-[Tris(hydroxymethyl) methyl]-2-aminoethanesulfonic acid), $\mathrm{pH} 7.4,250 \mathrm{mM}$ sucrose, $1 \mathrm{mM}$ EDTA, $2 \mathrm{mM}$ ethylene glycol tetraacetic acid (EGTA), $40 \mathrm{mM}$ phenyl-phosphate, $5 \mathrm{mM}$ sodium fluoride, $1 \mathrm{mM}$ dithiothreitol (DTT), $50 \mu \mathrm{M}$ sodium vanadate, Pefabloc (Sigma), Complete (Roche, protease inhibitors) and $1 \% \mathrm{NP} 40(200 \mu \mathrm{L} /$ well $)$ and subjected to sonication (10 short pulses). The lysates were centrifuged for $5 \mathrm{~min}$ at $5000 \times \mathrm{g}, 4^{\circ} \mathrm{C}$ and the supernatants were used for further analysis.

\section{SDS-PAGE and western blot analysis}

HEI-OC1 cell lysates $(20-30 \mu \mathrm{g}$ protein as measured by Bradford) were mixed with LDS (Lauryl Dodecyl Sulphate) sample buffer 4X (Invitrogen) containing $300 \mathrm{mM}$ DTT and subjected to electrophoresis on
4\%-12\% bisacrylamide gels (Novex, Invitrogen). Proteins were transferred to Immobilon-P, PVDF (Polyvinylidene Fluoride) membranes (Merck Millipore), blocked with $10 \%$ milk in Tris-buffered saline tween-20 $(50 \mathrm{mM}$ Tris, $\mathrm{pH} 7.6,150 \mathrm{mM} \mathrm{NaCl}$ and $0.1 \%$ Tween-20) for $30 \mathrm{~min}$ and incubated at $4{ }^{\circ} \mathrm{C}$ overnight with primary antibodies as indicated. Membranes were incubated with secondary antibody conjugated with horseradish peroxidase (HRP) for 1 hour at room temperature, incubated with SuperSignal West Pico ECL (enzymatic chemiluminescence) reagent (Thermo Scientific, Rockford, USA) for $10 \mathrm{~min}$ followed by imaging (Molecular Imager ChemiDoc XRS+, Bio-Rad Laboratories, Solna, Sweden) and quantification (Image lab software, V.3.0, Bio-Rad Laboratories).

\section{Total internal reflection fluorescence imaging}

HEI-OC1 cells were cultured on glass-bottom dishes (MatTek) and preincubated as described for 2 hours in Krebs-Ringer bicarbonate buffer containing $2 \mathrm{mM}$ glucose, $10 \mathrm{mM}$ HEPES, pH 7.4, $120 \mathrm{mM} \mathrm{NaCl}, 5 \mathrm{mM}$ $\mathrm{NaHCO}_{3}, 5 \mathrm{mM} \mathrm{KCl}, 1.2 \mathrm{mM} \mathrm{KH} \mathrm{PO}_{4}, 2.5 \mathrm{mM} \mathrm{CaCl}$, $1.2 \mathrm{mM} \mathrm{MgSO}$ and $0.2 \% \mathrm{BSA}$ at $33^{\circ} \mathrm{C}$. The cells were stimulated without or with $10 \mathrm{nM}$ insulin for $7 \mathrm{~min}$. Subsequently, the cells were fixed using $4 \%$ paraformaldehyde and incubated with antibodies as indicated (1 hour per primary antibody and 1 hour per secondary antibody) in a buffer containing $1 \%$ BSA, $1 \%$ goat serum and $0.05 \%$ 

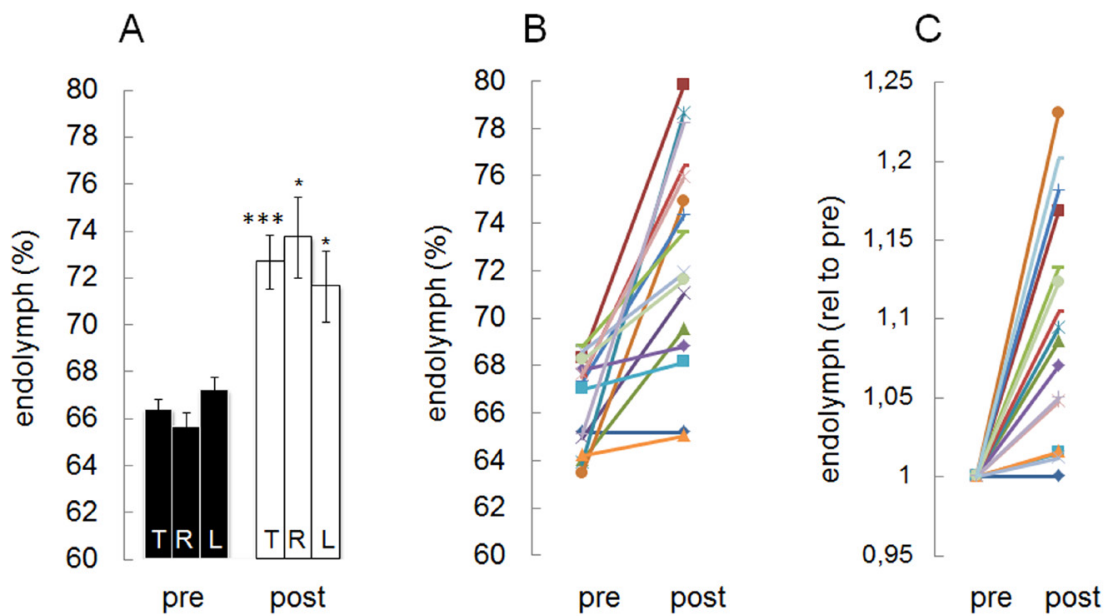

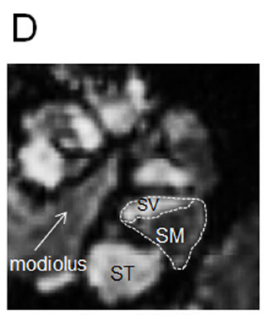

before HFD

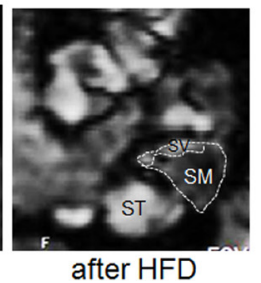

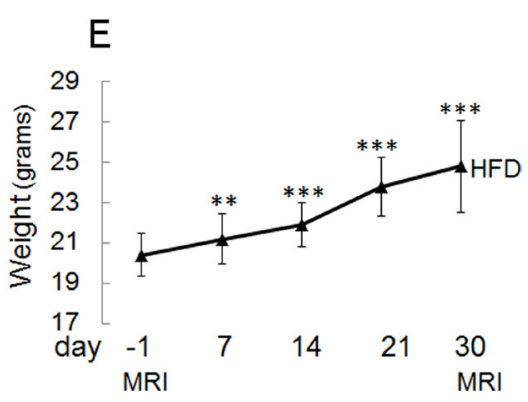

Figure 2 High fat diet (HFD) feeding induces expansion of the endolymphatic fluid compartment in C57BL/6J mice when comparing the same ear before and after feeding. $(A-C)$ Data are presented as: $(A)$ means \pm SEM corresponding to all animals in the study shown for all ears (T), right ears (R) and left ears (L) (mean \pm SEM: before HFD (pre), $66.4 \pm 0.50(T), 65.6 \pm 0.7(R)$,


(B) as individual values before and after HFD and (C) as individual values for each ear with prevalues set to 1. (D) Example of images parallel to the modiolus of cochlea analyzed by MRI both before and after HFD feeding is shown. The gadolinium contrast moves into the perilymph (SV and ST), but not into the endolymph (SM), therefore the perilymph looks white and the endolymph looks black. Note the significant decrease in SV relative area after HFD feeding. The relative area of SM in the basal turn of the cochlea was estimated as described in 'Methods' section. The ratio of areas was subsequently converted to percentage as shown in A-C. SV, scala vestibule; ST, scala tympani; SM, scala media. (E) Time course in changes in body weight from baseline at 8 weeks of age and during 30 days on HFD (eight mice). MRI was performed at days indicated. Data are presented as means $\pm S D$. ${ }^{\star} \mathrm{P}<0.05,{ }^{* \star} \mathrm{p}<0.01,{ }^{\star \star \star} \mathrm{p}<0.001$ vs day -1 .

saponin. To visualize actin the cells were incubated with phalloidin (Invitrogen) for 1-2 hours.

For total internal reflection fluorescence (TIRF) imaging we used a commercial TIRF system based on a Nikon Ti-E eclipse microscope equipped with a $100 \times$ Apo TIRF DIC oil immersion objective with a NA of 1.49 (Nikon Instruments), an iXon Ultra DU-897 EMCCD camera (Andor Technology) and four main laser lines: 405 (Cube, Coherent), 488 (Melles-Griot), 561 (Sapphire, Coherent) and 640 (Cube, Coherent) with corresponding filter sets.

\section{Antibodies}

The following primary antibodies were used for western blot analysis/TIRF microscopy as indicated: pACC Ser79 \#3661, ACC\#3662, pPKBSer473 \#9271, PKB \#9272, pAMPK Thr172 \#2535, anti-AMPK \#2603 (all from Cell Signalling), PDE1B and PDE4D antibodies were from Scottish Biomedical, the PDE3B antibody was made in house, Hsp 90 (610418, BD Biosciences), GAPDH (Sigma-Aldrich, St
Louis, Missouri, USA), fatty acid synthase (FAS) (sc20140) were from Santa Cruz. Antirabbit and antimouse secondary antibodies conjugated to HRP were from Thermo Fisher Scientific (Rockford, Illinois, USA) and GE Healthcare (Little Chalfont, UK), respectively.

\section{Immunoprecipitation and in vitro assay of AMP-activated kinase activity}

Lysates containing $5 \mu \mathrm{g}$ of protein were incubated at $4^{\circ} \mathrm{C}$ for 1-2hours on a shaking platform with $2 \mu \mathrm{g}$ AMPK $\alpha 1$ antibody generated in house by immunizing rabbits with a peptide encompassing residues 344-358 of rat AMPK $\alpha 1$ (TSPPDSFLDDHHLTR) (Innovagen, Lund, Sweden), conjugated to $5 \mu \mathrm{L}$ packed protein G-Sepharose (GE Healthcare Biosciences, Uppsala, Sweden). AMP-activated kinase (AMPK) assay was performed exactly as previously described using AMARA peptide (AMARAASAAALARRR) (GL Biocem, Shanghai) as substrate (for $20 \mathrm{~min}$ at $30^{\circ} \mathrm{C}$ ).$^{25}$ Incorporation of ${ }^{32} \mathrm{P}$-phosphate was expressed as pmol ATP incorporated $/ \mathrm{mg}$ protein $/ \mathrm{min}(\mathrm{mU} / \mathrm{mg})$. 


\section{Measurement of PDE activity}

HEI-OC1 cells were harvested in PDE buffer containing $50 \mathrm{mM}$ TES, pH 7.4, $250 \mathrm{mM}$ sucrose, $1 \mathrm{mM}$ EDTA, $1 \mathrm{mM}$ DTT and Complete (Roche, protease inhibitors) $(200 \mu \mathrm{L} /$ well) and subjected to sonication $(2 \times 10$ pulses). Homogenates were centrifuged for $5 \mathrm{~min}$ at $5000 \times \mathrm{g}$. PDE1 and PDE4 activities were measured in the supernatants. PDE3 activity was measured in a membrane fraction. The $5000 \times \mathrm{g}$ supernatant was centrifuged at $100000 \times \mathrm{g}$ for $60 \mathrm{~min}$ at $4^{\circ} \mathrm{C}$ and membranes were suspended in PDE buffer $(500 \mu \mathrm{L} /$ plate). The following PDE inhibitors were used at final concentrations: $10 \mu \mathrm{M}$ of the PDE3 inhibitor OPC3911 (Osaka, Japan), $10 \mu \mathrm{M}$ of the PDE4 inhibitor RO-20 (Roche) and $50 \mu \mathrm{M}$ of the PDE1 inhibitor 8MM-IBMX (Enzo Life Science, Farmingdale, New York, USA). The non-selective PDE inhibitor IBMX was used at $100 \mu \mathrm{M}$ final concentration. Assays were performed at $30^{\circ} \mathrm{C}$ in a total volume of $300 \mu \mathrm{L}$ of buffer containing $50 \mathrm{mM}$ TES $\mathrm{pH} 7.4,250 \mathrm{mM}$ sucrose, $1 \mathrm{mM}$ EDTA, $0.1 \mathrm{mM}$ EGTA and $8.3 \mathrm{mM} \mathrm{MgCl}_{2}$, $0.5 \mu \mathrm{M}$ cAMP, $0.5 \mu \mathrm{g}$ ovalbumin and $1 \mu \mathrm{Ci} / \mathrm{mL}{ }^{3} \mathrm{H}$ cAMP $(55000-65000 \mathrm{cpm}){ }^{26}$

\section{Measurement of hormone-sensitive lipase activity}

HEI-OC1 cells and mouse adipose tissue were homogenized in $0.25 \mathrm{M}$ sucrose, $1 \mathrm{mM}$ EDTA, $1 \mathrm{mM}$ DTE and protease inhibitors $(20 \mu \mathrm{g} / \mathrm{mL}$ leupeptin, $2 \mu \mathrm{g} / \mathrm{mL}$ antipain, $1 \mu \mathrm{g} / \mathrm{mL}$ pepstatin), $\mathrm{pH} 7.0$, using a glass-glass homogenizer. To remove fat from the adipose tissue homogenate, it was centrifuged at $110000 \times \mathrm{g}$ for 1 hour at $4^{\circ} \mathrm{C}$ and the fat-free infranatant was used for hormonesensitive lipase (HSL) activity measurements. As a positive control in the HSL activity measurements, recombinant rat HSL was used. Measurement of HSL activity was performed using 1 (3)-oleoyl-2-0-oleylglycerol, a diacylglycerol analogue, as substrate, as described in detail by Osterlund and Holm. ${ }^{27}$ To estimate the fraction of activity accounted for by HSL, samples were pre-incubated with either an activity-neutralizing hen antirat HSL serum (prepared in-house) or pre-immune serum for $15 \mathrm{~min}$ at $37^{\circ} \mathrm{C}$ prior to the assay. Total protein content of the samples was measured using the Bradford method and activity was expressed as $\mathrm{mU} / \mathrm{mg}$ protein, where $1 \mathrm{U}$ corresponds to the release of $1 \mu \mathrm{mol}$ of fatty acids per $\min$ at $37^{\circ} \mathrm{C}$.

\section{Statistical analysis}

Results are expressed as mean \pm SEM. Differences between groups were tested for statistical significance using paired or non-paired Student's t-test. P values $<0.05$ were considered to denote statistical significance.

\section{RESULTS}

\section{Impact of insulin resistance on mouse inner ear}

As shown in figure 1A-D, mice fed HFD showed significantly larger EFCs compared with mice fed CD. HFDinduced hydrops developed in the right as well as in the left ears (figure 1C). The body weight of mice fed HFD was significantly higher after 14, 21 and 30 days, respectively, compared with the body weight of mice fed $\mathrm{CD}$ (figure 1E).

We also performed a longitudinal study of the effect of HFD on the size of the EFC in C57BL/6J mice, both before and after 30 days of HFD feeding. As shown in figure 2A,D, HFD significantly induced an expansion of the EFC. HFD-induced hydrops developed in the right as well as in the left ears (figure 2A). In figure 2B, prevalues and postvalues are shown for each ear and in figure $2 \mathrm{C}$, the pretreatment value was set to 1 for each ear. After the initiation of HFD feeding, significant weight gain was obtained after 7, 14, 21 and 30 days (figure 2E).

Thus, in agreement with the known association between diabetes and inner ear dysfunction, mice with HFD-induced insulin resistance develop EH.

The organ of Corti was recently shown to express the insulin receptor. ${ }^{17}$ To investigate whether the cochlea could be a direct target for insulin signaling, we used HEI-OC1 auditory cells as a model for organ of Corti cells.

\section{Insulin induces phosphorylation of PKB in HEl-0C1 cells}

Insulin induced a dose-dependent and time-dependent phosphorylation of PKB at the activity-controlling site Ser473 (figure 3A,B) in the plasma membrane in HEIOC1 auditory cells (figure 3C). Cells were co-stained with actin to confirm that image analysis was done close to the plasma membrane (figure 3C, upper panel).

Insulin-induced phosphorylation of PKB was blocked by wortmannin, a PI3-kinase inhibitor, isoproterenol, a $\beta$-adrenergic receptor agonist and by IBMX, a general PDE inhibitor (figure 3D-F). Rolipram (PDE4 inhibitor), 8MM IBMX (PDE1 inhibitor) or cilostamide (PDE3 inhibitor) did not significantly antagonize the insulininduced effect (data not shown), although the respective PDE subtype was expressed (figure 3G lower panel) and catalytically active (figure 3G upper panel) in HEI-OC1 cells.

\section{Insulin decreases and AICAR increases phosphorylation of acetyl-CoA carboxylase in HEl-0C1 cells}

Insulin lowered the phosphorylation of acetyl-CoA carboxylase (ACC) at Ser79, an inhibitory phosphorylation site (figure 4A). AICAR, an AMPK activator, in turn increased ACC Ser79 phosphorylation (figure 4B). AMPK activation was verified by increased Thr172 phosphorylation (figure 4C) and increased in vitro kinase activity (figure 4D). FAS, the enzyme complex catalyzing the synthesis of fatty acids (figure $4 \mathrm{~F}$ ) as well as HSL, the rate-limiting enzyme in lipolysis (figure $4 \mathrm{E}$ ), were expressed in HEI-OC1 cells. Lipase activity, as measured using a diacylglycerol analogue as substrate, was inhibited to approximately $50 \%$ by an HSL antiserum, whereas diacylglycerol lipase activity in an adipose tissue homogenate as well as that of recombinant HSL were completely inhibited (figure 4E). 

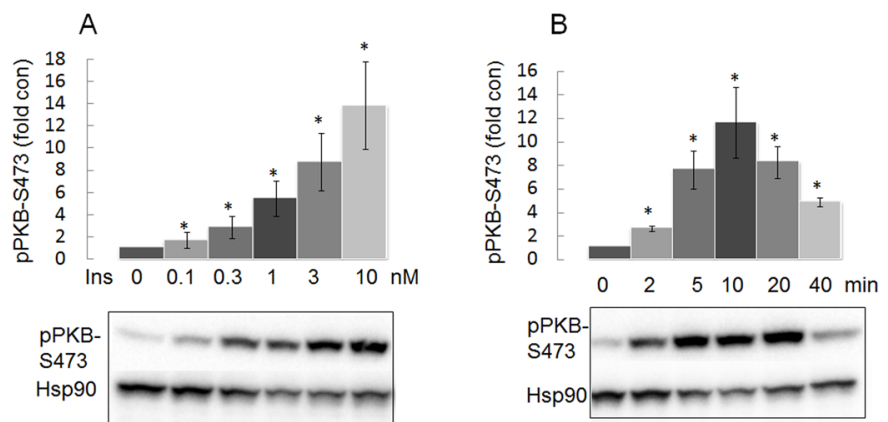

E




Figure 3 Insulin (ins) induces phosphorylation of protein kinase B (PKB) in the plasma membrane of House Ear InstituteOrgan of Corti 1 (HEl-OC1) auditory cells. (A) HEl-OC1 cells were stimulated with different concentrations of ins for 10 min $(n=4-6)$ and $(B)$ with $1 \mathrm{nM}$ ins for 0-40 min ( $n=3-6)$. Phosphorylation of PKB was analyzed by western blot analysis using PKB Ser473 antibody. (C) Total internal reflection fluorescence (TIRF) imaging was performed on HEI-OC1 cells stimulated without or with $10 \mathrm{nM}$ ins for 7 min prior to fixation and cells co-stained with PKB Ser473 antibody and actin antibody (upper panel) or with PKB Ser473 antibody (lower panel). A representative image from three experiments is shown. Scale bar=20 $\mu m$. (D) HEIOC1 cells were stimulated without or with ins $(1$ and $10 \mathrm{nM})$ for 30 min without or with $100 \mu \mathrm{M}$ wortmannin (wort) (added 30 min before ins) (n=3), (E) $10 \mathrm{nM}$ ins with or without $30 \mathrm{nM}$ isoproterenol (iso) $(n=4)$ or (F) $1 \mathrm{nM}$ ins with or without $100 \mu M$ IBMX ( $\mathrm{n}=6)$. Phosphorylation of PKB was analysed by western blot analysis using PKB Ser473 antibody (samples are shown in duplicate for $\mathrm{E}$ and F). (G) Total cell lysates or membrane fractions (for measurement of phosphodiesterase (PDE)3 activity) were assayed for PDE1 (inhibited by 8 MM IBMX) $(n=5)$, PDE4 (inhibited by rolipram) $(n=5)$ and PDE3 (inhibited by cilostamide) ( $n=4)$ and also for PDE activity inhibited by IBMX (IBMX inhibitable (i) PDE) $(n=5)$, as indicated. Western blot analysis using PDE4D, PDE1B and PDE3B antibodies are shown (lower panel). Blots are representative of three to six independent experiments. pPKB western blot analysis signals were normalized to untreated control samples not stimulated by ins $(A, B, D, E)$ or to samples stimulated with ins only $(F)$. Data are presented as means \pm SEM. ${ }^{*} P<0.05,{ }^{\star * *} p<0.001$ vs control $(A, B, D, E),+p<0.05$ vs ins only $(D, E, F)$. Hsp90, heat shock protein 90.

\section{DISCUSSION}

In this study, we investigated the presence and size of $\mathrm{EH}$ in HFD-fed C57BL/6J mice using MRI and gadolinium, ${ }^{2022} 23$ and insulin signaling in HEI-OC1 auditory cells. Importantly, the development of $\mathrm{EH}$ was used as a marker for inner ear dysfunction, but the mechanisms involved in hydrops development were not addressed. Our results indicate that HFD-fed C57BL/6J mice indeed develop inner ear $\mathrm{EH}$ and that insulin signaling takes place in HEI-OC1 cells.
C57BL/6J mice fed HFD is a robust and widely used model to study effects of insulin resistance, impaired glucose homeostasis and early type 2 diabetes. ${ }^{21}$ In a recent study from our laboratory, using the same batch of HFD and the same mouse strain, the onset of insulin resistance and lowering of insulin-induced phosphorylation of PKB was noted already after 2 days on HFD. ${ }^{28}$

Our present results, indicating dysfunction of the inner ear by HFD feeding using $\mathrm{EH}$ as a read-out, agree with several previous studies showing HFD-induced damage to 



$\mathrm{E}$

\begin{tabular}{|c|c|c|}
\hline & $\begin{array}{c}\text { DAG lipase } \\
\text { activity } \\
\text { (mU/mg } \\
\text { protein) }\end{array}$ & $\begin{array}{c}\text { HSL activity } \\
\text { (mU/mg } \\
\text { protein) }\end{array}$ \\
\hline HEI-OC1 cells & $2.5 \pm 0.1$ & $1.2 \pm 0.1$ \\
\hline Adipose tissue & $317 \pm 17$ & $313 \pm 8$ \\
\hline $\begin{array}{c}\text { Recombinant } \\
\text { HSL }\end{array}$ & $31622 \pm 954$ & $31378 \pm 206$ \\
\hline
\end{tabular}
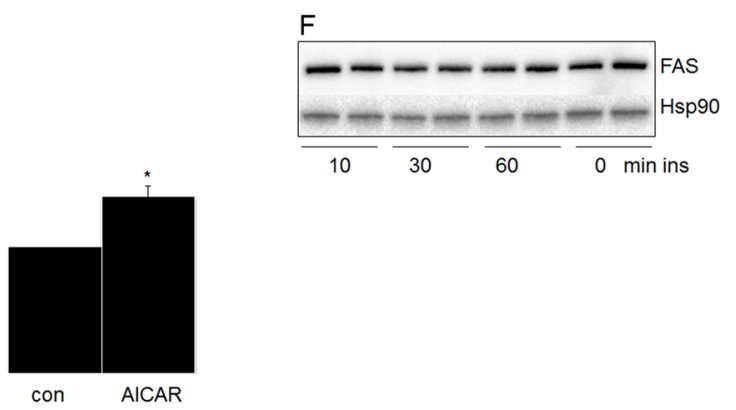

Figure 4 Insulin decreases and AICAR increases the phosphorylation of acetyl-CoA carboxylase (ACC) in House Ear InstituteOrgan of Corti 1 (HEl-OC1) cells. (A) HEI-OC1 cells were stimulated without or with $1 \mathrm{nM}$ insulin for 0-60 min ( $\mathrm{n}=4)$ or $(B-D)$ with $1 \mathrm{mM}$ AICAR $(n=3)$ for $60 \mathrm{~min}$. The phosphorylation state of ACC and AMP-activated kinase (AMPK) were analyzed by western blot analysis using ACC Ser79 (A, B) and AMPK Thr172 (C) antibodies and the activity state of AMPK was measured against the peptide substrate AMARA in AMPK immunoprecipitates $(n=3)(D)$. Blots are representative of three to four independent experiments (samples are shown in duplicate). pACC and pAMPK western blot analysis signals were normalized to control samples not stimulated by insulin or AICAR. For effect of insulin on ACC phosphorylation (A), the 20 min time point was used for quantification. (E) Hormone-sensitive lipase (HSL) activity was determined by immune-inhibition and compared with a control sample incubated with a preimmune serum as described in 'Methods' section $(n=3)$. ( $F)$ HEI-OC1 cells were stimulated without or with $10 \mathrm{nM}$ insulin for 0-60 min. The expression of FAS was analyzed by western blot analysis using FAS antibody, shown is a representative blot. Data are presented as means $\pm S E M .{ }^{*} \mathrm{P}<0.05,{ }^{\star \star} \mathrm{p}<0.01 \mathrm{vs}$ control (con) (A-D). DAG, diacylglycerol; FAS, fatty acid synthase; GAPDH, glyceraldehyde-3-phosphate dehydrogenase; Hsp90, heat shock protein 90; ins, insulin.

the inner ear. ${ }^{102930}$ To our knowledge, the development in vivo of $\mathrm{EH}$ using MR and gadolinium has not previously been reported on in the context of insulin resistance and diabetes. Furthermore, it should be noted that in the present study EH developed already after 4 weeks of HFD feeding.

It should be noted that type 1 diabetes and type 2 diabetes could impact on the auditory systems by common mechanisms related to hyperglycemia. However, insulin resistance or hyperinsulinemia, characteristic features of type 2 diabetes, may cause damage via separate mechanisms. ${ }^{1011}$ Thus, development of EH in our study could be related to systemic hyperglycemia and/or insulin resistance/hyperinsulinemia. It has been shown that administration of insulin to guinea pigs leads to reduction in $\left[\mathrm{K}^{+}\right]$and increase in $\left[\mathrm{Na}^{+}\right]$in the endolymph, which, by increasing the osmotic pressure, could result in EH. ${ }^{13} 14$ Furthermore, administration of insulin to guinea pigs has been shown to reduce cochlear microphonics and administration of insulin to sheep showed reductions in DPOAE indicating loss of outer hair cells' function. ${ }^{15} 16$ Interestingly, in a recent cross-sectional study insulin resistance, impaired fasting glucose and beta-cell dysfunction were reported as independent risk factors for impaired hearing. 12

Development of $\mathrm{EH}$ could also be related to altered levels of adipose tissue-derived factors such as increased flux of free fatty acids, increased release of proinflammatory cytokines and altered secretion of adipokines. ${ }^{31}$ Interestingly, adiponectin, one of the major adipokines released from adipocytes, was suggested to be a mediator of obesity-associated, age-related hearing impairment. $^{32}$

The finding that classical insulin signaling, involving the PI3-kinase/PKB node, takes place in HEI-OC1 cells agrees with a recent study showing the expression of the insulin receptor in supporting cells of the organ of Corti from mouse ${ }^{17}$ and also with the expression of insulin signaling components in the human saccule sensory epithelium. ${ }^{1920}$ Regarding the PI3-kinase/PKB signaling node, several studies have demonstrated that a decrease in PI3-kinase/PKB signaling in the organ of Corti cells is associated with hearing loss. ${ }^{33}$ Also, following aminoglycoside treatment, PI3-kinase/PKB signaling has been shown to protect against gentamycin ototoxicity in explants of the organ of Corti. ${ }^{35}$ These results 
are compatible with a negative impact of organ of Corti insulin resistance on hearing.

The cross-talk between insulin and cAMP is highly relevant, cAMP being a key component in the regulation of ion and fluid homeostasis in the inner ear. ${ }^{36}{ }^{37}$ For example, as in the kidney, in the inner ear vasopressin acts on aquaporin 2 and fluid transport via increases in cAMP. $^{36}$ The findings that IBMX, a general PDE inhibitor, could mimic the ability of isoproterenol to reduce the insulin signaling capacity indicates a role for PDEs in the cross-talk with insulin. The expression of cAMPdegrading and cGMP-degrading enzymes PDE1B, PDE3B and PDE4D in HEI-OC1 auditory cells is in agreement with previous results showing the expression of these and other PDE family members in the human saccule ${ }^{1938}$ and with results showing the development of $\mathrm{EH}$ in response to PDE3 and PDE4 inhibitors. ${ }^{20}$ However, we could not demonstrate a connection between PDE1, PDE3 or PDE4 and insulin signaling in HEI-OC1 cells such as that shown in adipocytes and hepatocytes, where insulin lowers cAMP by activating PDE3B. ${ }^{39}$

Our results indicate that enzymes involved in de novo lipogenesis and lipolysis, ACC, FAS and HSL, are expressed in HEI-OC1 cells, and that insulin lowers the phosphorylation of ACC. The latter is presumably associated with increased synthesis of fatty acids and formation of triglycerides. We also show that phosphorylation of ACC increased when cells were incubated with AICAR, an activator of AMPK, a major regulator of cellular energy homeostasis. Altered expression/activity of AMPK in the organ of Corti has previously been shown to protect against as well as promote hearing loss following acoustic overstimulation. ${ }^{40} 41$ The role of ACC in AMPK-mediated effects on hearing remains to be clarified.

Interestingly, lipid droplets have been detected in Hensen cells in the auditory organ and it has been suggested that these droplets have an important role in inflammatory responses in the cochlea. ${ }^{42}$ In adipocytes, the main role for HSL is to catalyze the hydrolysis of stored triacylglycerols during periods of energy shortage. ${ }^{39}$ In addition to the generation of energy substrates, HSL could also provide the auditory cells with lipid signaling molecules, for example, long-chain acyl-CoA and diacylglycerol (DAG) which has been described in other cell types, for example, in pancreatic beta-cells. ${ }^{43}$ In various non-adipocyte-producing or non-steroid-producing cells, including beta-cell lines and in rat and mouse islets, DAG lipase activity has been reported in the range of 2.2-9.2 $\mathrm{mU} / \mathrm{mg}$ protein and HSL immuno-inhibition was from $22 \%$ to $77 \%{ }^{43}$ in agreement with our results in HEI-OC1 cells.

In conclusion, insulin might impact on the organ of Corti by mechanisms used in classical target cells for insulin action. Thus, defects in inner ear insulin action could contribute to the previously described association between diabetes and inner ear dysfunction. ${ }^{1-5}$ It is possible that direct effects of insulin signaling on regulatory systems for fluid and ion homeostasis as well as energy metabolism act as a new regulatory mechanism for the organ of Corti in normal situations and in disease. Although in the present study mechanisms for the development of $\mathrm{EH}$ have not been addressed, it is possible that defects in insulin action in the organ of Corti contributes to the development of $\mathrm{EH}$ since the vasopressin/ aquaporin 2 system as well as key ion transporters, Na,KATPase and the sodium transporter Enac, are known to be expressed in the organ of Corti. ${ }^{44-47}$ Interestingly, in kidney cells, insulin has been shown to regulate these transporters. ${ }^{48}{ }^{49}$ On the other hand, EH could just be a marker for risk to develop inner ear/cochlear dysfunction independent of the causative etiology, perhaps making the organ of Corti cells more vulnerable to metabolic stressors, such as dysregulated glucose homeostasis and insulin resistance/hyperinsulinemia. Glucose is considered to be the primary energy source for the cochlea and interestingly, insulin-dependent glucose uptake in the organ of Corti was recently reported.$^{17}$ Although there is no indication that cells from the stria vascularis express insulin receptors, ${ }^{17}$ we plan to investigate them in the near future because of their key role in the production of the endolymph. However, we anticipate problems in separating the contribution of cells from the cochlea and the stria vascularis since the composition of the endolymph and the endocochlear potential depends both on the active electrogenic extrusion of $\mathrm{K}^{+}$into the scala media by the stria vascularis and by the passive drainage of $\mathrm{K}^{+}$from scala media, largely through the hair cells in the organ of Corti. ${ }^{50}$

\section{Study limitation and future research}

We used MR and gadolinium contrast to demonstrate an expansion of the EFC as a marker for inner ear dysfunction in the context of HFD/insulin resistance. A limitation of this study, however, is that we have not directly investigated mice cochleae in regard to morphology (IHC), protein expression and, most important, we did not provide direct evidence that the cochlea in vivo is a target of insulin action or resistance. It will be important to link such mechanisms to (dys) regulation of inner ear fluid and energy homeostasis, and we plan to address these questions in upcoming studies. It will also be of importance to take into consideration the interaction between type 2 diabetes and age-induced hearing loss, since it has been shown in animal models that age-induced hearing loss is enhanced by diabetes. ${ }^{59}$

\section{Author affiliations}

${ }^{1}$ Experimental Medical Science, Section for Diabetes, Metabolism and Endocrinology, Lund University Diabetes Centre, Lund University, Lund, Sweden

${ }^{2}$ Lund University Bioimaging Center, Lund University, Lund, Sweden

${ }^{3}$ Department of Head and Neck Surgery, Laboratory of Auditory Cell Biology, David Geffen Schoolof Medicin, UCLA, Los Angeles, California, USA

${ }^{4}$ Department of Clinical Science, Section for Otorhinolaryngology, Lund University \& Skåne University Hospital, Lund, Sweden

Acknowledgements Lund University Bioimaging Center (LBIC) is gratefully acknowledged for providing experimental resources. ED, A-KP, FK, BM, KS, OG, CH are affiliated with Lund University Diabetes Center (LUDC). 
Contributors $\mathrm{ED}, \mathrm{MM}, \mathrm{CH}, \mathrm{A}-\mathrm{KP}$ conceived the study and designed the experiments. A-KP, FK, BM, RIZ conducted the experiments. A-KP, FK, ED, CH analyzed the data. ED drafted and FK helped to edit the manuscript. All authors interpreted the data, contributed to discussion and critically revised the manuscript and figures. All authors approved the final version of this manuscript. ED is responsible for the integrity of the work as a whole.

Funding The work was supported by grants from the Swedish Medical Research Council Dnr 2019-01246, the Swedish Diabetes Foundation, the Swedish Foundation for Strategic Research Dnr IRC 15-0067, the Albert Påhlsson Foundation, Sweden, the Crafoord Foundation, Sweden, Diabetes Wellness Sweden, Skane County Council's Research and Development Foundation, Sweden and the Faculty of Medicin, Lund University, Sweden. The authors alone are responsible for the content and writing the paper.

Competing interests None declared.

Patient consent for publication Not required.

Ethics approval All animal procedures were approved by the Regional Ethical Committee for Animal Experiments in Malmö/Lund.

Provenance and peer review Not commissioned; externally peer reviewed.

Data availability statement Data are available on reasonable request. All data relevant to the study are included in the article or uploaded as supplementary information. To obtain MR raw data contact the corresponding author ED (eva. degerman@med.lu.se) to obtain images as zipped dicoms. All other data relevant for the study are included in the article.

Open access This is an open access article distributed in accordance with the Creative Commons Attribution Non Commercial (CC BY-NC 4.0) license, which permits others to distribute, remix, adapt, build upon this work non-commercially, and license their derivative works on different terms, provided the original work is properly cited, appropriate credit is given, any changes made indicated, and the use is non-commercial. See: http://creativecommons.org/licenses/by-nc/4.0/.

\section{ORCID iDs}

Franziska Kopietz http://orcid.org/0000-0002-7912-8853

Eva Degerman http://orcid.org/0000-0001-6664-3752

\section{REFERENCES}

1 Mujica-Mota MA, Patel N, Saliba I. Hearing loss in type 1 diabetes: are we facing another microvascular disease? A meta-analysis. Int $J$ Pediatr Otorhinolaryngol 2018;113:38-45.

2 Teng Z-P, Tian R, Xing F-L, et al. An association of type 1 diabetes mellitus with auditory dysfunction: a systematic review and metaanalysis. Laryngoscope 2017;127:1689-97.

3 Akinpelu OV, Mujica-Mota M, Daniel SJ. Is type 2 diabetes mellitus associated with alterations in hearing? A systematic review and meta-analysis. Laryngoscope 2014;124:767-76.

4 D'Silva LJ, Lin J, Staecker H, et al. Impact of diabetic complications on balance and falls: contribution of the vestibular system. Phys Ther 2016;96:400-9.

5 Elangovan S, Spankovich C. Diabetes and Auditory-Vestibular pathology. Semin Hear 2019;40:292-9.

6 Akinpelu OV, Ibrahim F, Waissbluth S, et al. Histopathologic changes in the cochlea associated with diabetes mellitus-a review. Otol Neurotol 2014;35:764-74.

7 Fukushima H, Cureoglu S, Schachern PA, et al. Effects of type 2 diabetes mellitus on cochlear structure in humans. Arch Otolaryngol Head Neck Surg 2006;132:934-8.

8 Hong O, Buss J, Thomas E. Type 2 diabetes and hearing loss. Dis Mon 2013;59:139-46.

9 Frisina ST, Mapes F, Kim S, et al. Characterization of hearing loss in aged type II diabetics. Hear Res 2006;211:103-13.

10 Vasilyeva ON, Frisina ST, Zhu X, et al. Interactions of hearing loss and diabetes mellitus in the middle age CBA/CaJ mouse model of presbycusis. Hear Res 2009;249:44-53.

11 Hong BN, Kang TH. Distinction between auditory electrophysiological responses in type 1 and type 2 diabetic animal models. Neurosci Lett 2014;566:309-14.

12 Seo M, Lee Y-S, Moon S-S. Association of hearing impairment with insulin resistance, $\beta$-cell dysfunction and impaired fasting glucose before onset of diabetes. Diabet. Med. 2016;33:1275-82.

13 Albernaz PL, Loss $\mathrm{H}$. Dizziness, and carbohydrate metabolism. Int Arch Otorhinolaryngol 2016;20:261-70.

14 Mendelsohn M, Roderique J. Cationic changes in endolymph during hypoglycemia. Laryngoscope 1972;82:1533-40.
15 Koide Y, Tajima S, Yoshida M, et al. Biochemical changes in the inner ear induced by insulin, in relation to the cochlear microphonics. Ann Otol Rhinol Laryngol 1960;69:1083-97.

16 Zuma e Maia FC, Lavinsky L. Distortion product otoacoustic emissions in an animal model of induced hyperinsulinemia. Int Tinnitus J 2006;12:133-9.

17 Huerzeler N, Petkovic V, Sekulic-Jablanovic M, et al. Insulin receptor and glucose transporters in the mammalian cochlea. Audiol Neurotol 2019;24:65-76.

18 Wang S, Schacht J. Insulin stimulates protein synthesis and phospholipid signaling systems but does not regulate glucose uptake in the inner ear. Hear Res 1990;47:53-61.

19 Degerman E, Rauch U, Lindberg S, et al. Expression of insulin signalling components in the sensory epithelium of the human saccule. Cell Tissue Res 2013;352:469-78.

20 Degerman E, In 't Zandt R, Pålbrink A, et al. Inhibition of phosphodiesterase 3, 4, and 5 induces endolymphatic hydrops in mouse inner ear, as evaluated with repeated 9.4T MRI. Acta Otolaryngol 2017;137:8-15.

21 Winzell MS, Ahrén B. The high-fat diet-fed mouse: a model for studying mechanisms and treatment of impaired glucose tolerance and type 2 diabetes. Diabetes 2004;53:S215-9.

22 Degerman E. In 't Zandt R, Pålbrink AK, Magnusson M.Vasopressin induces endolymphatic hydrops in mouse inner ear, as evaluated with repeated 9.4 T MRI. Hear Res 2015;330:119-24.

23 Degerman E, In 't Zandt R, Pålbrink A, et al. Endolymphatic hydrops induced by different mechanisms responds differentially to spironolactone: a rationale for understanding the diversity of treatment responses in hydropic inner ear disease. Acta Otolaryngol 2019;139:685-91.

24 Kalinec GM, Webster P, Lim DJ, et al. A cochlear cell line as an in vitro system for drug ototoxicity screening. Audiol Neurotol 2003:8:177-89.

25 Kopietz F, Berggreen C, Larsson S, et al. AMPK activation by A-769662 and 991 does not affect catecholamine-induced lipolysis in human adipocytes. Am J Physiol Endocrinol Metab 2018;315:E1075-85.

26 Degerman E, Resjö S, Landström TR, et al. Methods to study phosphorylation and activation of the hormone-sensitive adipocyte phosphodiesterase type 3B in rat adipocytes. Methods Mol Biol 2001:155:167-80.

27 Osterlund T, Holm C. Hormone-sensitive lipase and neutral cholesteryl lipase. Methods Mol Biol 1999;109:109-21.

28 Hansson B, Wasserstrom S, Morén B, et al. Intact glucose uptake despite deteriorating signaling in adipocytes with high-fat feeding. $J$ Mol Endocrinol 2018;60:199-211.

29 Hwang J-H, Hsu C-J, Yu W-H, et al. Diet-induced obesity exacerbates auditory degeneration via hypoxia, inflammation, and apoptosis signaling pathways in $\mathrm{CD} / 1$ mice. PLoS One 2013;8:e60730.

30 Du Z, Yang Y, Hu Y, et al. A long-term high-fat diet increases oxidative stress, mitochondrial damage and apoptosis in the inner ear of d-galactose-induced aging rats. Hear Res 2012;287:15-24.

31 Wozniak SE, Gee LL, Wachtel MS, et al. Adipose tissue: the new endocrine organ? A review article. Dig Dis Sci 2009;54:1847-56.

32 Hwang J-H, Hsu C-J, Liu T-C, et al. Association of plasma adiponectin levels with hearing thresholds in adults. Clin Endocrinol 2011;75:614-20.

33 Haake SM, Dinh CT, Chen S, et al. Dexamethasone protects auditory hair cells against TNF $\alpha$-initiated apoptosis via activation of PI3K/Akt and NFKB signaling. Hear Res 2009;255:22-32.

34 Chen J, Yuan $\mathrm{H}$, Talaska AE, et al. Increased sensitivity to noiseinduced hearing loss by blockade of endogenous PI3K/Akt signaling. JARO 2015;16:347-56.

35 Chung W-H, Pak K, Lin B, et al. A PI3K pathway mediates hair cell survival and opposes gentamicin toxicity in neonatal rat organ of Corti. J Assoc Res Otolaryngol 2006;7:373-82.

36 Takeda T, Takeda S, Kakigi A, et al. Hormonal aspects of Ménière's disease on the basis of clinical and experimental studies. ORL $J$ Otorhinolaryngol Relat Spec 2009;71:1-9.

37 Wangemann P. $\mathrm{K}^{+}$cycling and its regulation in the cochlea and the vestibular labyrinth. Audiol Neurootol 2002;7:199-205.

38 Degerman E, Rauch U, Göransson O, et al. Identification of new signaling components in the sensory epithelium of human saccule. Front Neurol 2011:2:48.

39 Degerman E, Ahmad F, Chung YW, et al. From PDE3B to the regulation of energy homeostasis. Curr Opin Pharmacol 2011:11:676-82.

40 Föller M, Jaumann M, Dettling J, et al. AMP-activated protein kinase in BK-channel regulation and protection against hearing loss following acoustic overstimulation. FASEB J 2012;26:4243-53. 
41 Hill K, Yuan H, Wang X, et al. Noise-Induced loss of hair cells and cochlear synaptopathy are mediated by the activation of AMPK. $J$ Neurosci 2016;36:7497-510.

42 Urrutia RA, Kalinec F. Biology and pathobiology of lipid droplets and their potential role in the protection of the organ of Corti. Hear Res 2015;330:26-38.

43 Mulder H, Holst LS, Svensson H, et al. Hormone-sensitive lipase, the rate-limiting enzyme in triglyceride hydrolysis, is expressed and active in beta-cells. Diabetes 1999;48:228-32.

44 Mhatre AN, Jero J, Chiappini I, et al. Aquaporin-2 expression in the mammalian cochlea and investigation of its role in Meniere's disease. Hear Res 2002;170:59-69.

45 Takumida M, Kakigi A, Egami N, et al. Localization of aquaporins 1,2 , and 3 and vasopressin type 2 receptor in the mouse inner ear. Acta Otolaryngol 2012;132:807-13.
46 McLean WJ, Smith KA, Glowatzki E, et al. Distribution of the Na,KATPase $\alpha$ Subunit in the Rat Spiral Ganglion and Organ of Corti. JARO 2009;10:37-49.

47 Zhong S-X, Hu G-H, Liu Z-H. Expression of ENaC, SGK1 and Nedd4 isoforms in the cochlea of guinea pig. Folia Histochem Cytobiol 2014;52:144-8.

48 Pao AC. There and back again: insulin, ENaC, and the cortical collecting duct. Physiol Rep 2016;4:pii: e12809.

49 Sweeney G, Klip A. Mechanisms and consequences of $\mathrm{Na}+, \mathrm{K}+-$ pump regulation by insulin and leptin. Cell Mol Biol 2011;47:363-72.

50 Patuzzi R. Ion flow in stria vascularis and the production and regulation of cochlear endolymph and the endolymphatic potential. Hear Res 2011;277:4-19. Review. 